Covered in: ERIH PLUS, HeinOnline, CEEOL, Index Copernicus, CrossRef, CrossCheck, J-GATE, Google Scholar, Ideas RePeC, Econpapers, Socionet, KVK, WorldCat.

\section{Settlement Methods of International Trade Disputes in the Pharmaceutical Industry: A Short Legal Empirical Research}

\section{Ștefan Răzvan TATARU1 \\ ${ }^{1} \mathrm{PhD}$ candidate at Alexandru Ioan Cuza University of Iași, Faculty of Law, email: razvantataru@gmail.com}

\begin{abstract}
The complexity of international trade agreements with pharmaceuticals is evidenced by the dynamics of the multitude of mechanisms and factors involved in contractual relations. The goal of the present research is represented by the analysis of the contractual clauses regarding dispute settlement used by pharmaceutical companies in international trade operations. Our study aims to analyze into details the challenges of settling and managing disputes arising from such agreements and to determine through empirical legal research, which ones are the specific dispute resolution means of such commercial operations. In the first part of the study, our research will target the legal counsels of pharmaceutical companies in order to determine, through the questionnaire method, the preferred dispute resolution practice and the applicable law in the international trade agreements. In the final part of this study, we are going to analyze the contractual clauses that are part of the international trade agreements with pharmaceuticals, with the purpose of validating the questionnaire's results.
\end{abstract}

Keywords: dispute resolution, international arbitration, legal empirical study, pharmaceutical industry, international trade disputes, settlement methods.

How to cite: Tataru, S..-R. (2018). Settlement Methods of International Trade Disputes in the Pharmaceutical Industry: A Short Legal Empirical Research. Logos Universality Mentality Education Novelty: Law, 6(1), 41-55. https://doi.org/10.18662/lumenlaw/06 


\section{Introduction}

The national and international legal doctrine (scientia iuris) presents arbitration as the main means of solving international trade disputes. Arbitration is an alternative form of dispute resolution which, due to the advantages it presents, is preferred to the detriment of the courts and even other amicable ways of settlement. Most international trade agreements contain a compromise clause whereby the parties agree that any future litigation will be settled by arbitration.

Arbitration is also the preferred method of settling pharmaceutical industry disputes due to important features such as the flexibility and confidentiality of the procedure, arbitrators' specialization and the binding award.

Given the international context of the pharmaceuticals trade and the complexity of the contracts that are governing these operations, the present study aims to analyse in detail the challenges of settling and managing disputes arising from such agreements and to determine through empirical legal research, which ones are the specific dispute resolution means of such commercial operations.

The undertaken empirical legal research comprises two sections with the same study object, emphasising the results obtained through different approaches. The first stage of our research targeted the legal counsels of pharmaceutical companies in order determine, through the questionnaire method, the preferred dispute resolution practice and the applicable law in the international trade agreements. The final stage consisted in the analysis of the contractual clauses, part of the international trade agreements with pharmaceuticals, with the purpose of validating the results obtained in the first stage of the research.

\section{Dispute resolution survey regarding the international trade contracts used in pharmaceutical industry}

\section{A. The questionnaire method}

The questionnaire consisted of ten questions with predefined multiple choice answers, also giving the respondent the possibility to provide a different response by filling in the other/others `section. The structure of the questionnaire was designed to contain only relevant research questions and to require as little time as possible for completion by the legal counsels of the pharmaceutical companies. 
The objective pursued by using the questionnaire method was to obtain real and direct feedback from the legal counsels of the pharmaceutical companies regarding the applicable law, the place and methods of dispute resolutions and the determinant criteria underlying these choices.

The questionnaire was built using the Google Forms platform, this choice being based on the internationally recognized popularity and security of Google's services. ${ }^{1}$

\section{$B$. The selection of the respondents}

Over one hundred sixty companies operating with pharmaceuticals in the international trade have been contacted for this study. They have been identified and selected using the following two methods: a) using the Google search results for the information on the top 20 worldwide pharmaceutical companies worldwide, and b) selecting them from the list of participants at CPhI WORLDWIDE International Trade Fair (an international fair, that is being organized annually, with at least 2500 companies from more than 150 countries), companies mainly engaged in the production and marketing of pharmaceuticals (either active pharmaceutical ingredients or finished products).

Following the identification and selection of one hundred sixty companies, based in more than thirty states worldwide, we have submitted to them the request to respond to the questionnaire. The request was sent electronically via the email addresses that have been identified on the targeted companies' websites, in the contact section. If the company's email address could not be identified, the request was sent via the online contact form, available on its website. The request was sent to the attention of the staff of the legal departments of the pharmaceutical companies, being the ones targeted by the questionnaire.

In order to directly disseminate the questionnaire to the targeted persons, we also used social networks for professionals, such as LinkedIn.com, through which we submitted the request to participate in the questionnaire in groups destined for practitioners of pharmaceutical law and/or international trade law.

\section{Questionnaire results}

Within the thirty days of the questionnaire broadcast, which was considered the reasonable amount of time for completing the survey, we received responses from twenty-two companies that are activating in the

\footnotetext{
The questionnaire can be accessed at the following link: https://goo.gl/forms/CDurRMJO5BvU7cTa2.
} 
international pharmaceutical trade, accounting for $13.8 \%$ of all companies contacted. Over the same period of time, thirteen companies expressed their strong refusal to participate in such study, invoking the violation of data privacy policies or the impossibility of allocating resources to respond to the request. The respondent companies are established in the following countries: Austria, Finland, France, Germany, Greece, India, Italy, Poland, Philippines, Romania, South Korea, Sweden, United States of America, Ukraine and United Kingdom of Great Britain and Ireland.

Subsequent to the collection of responses, these have been analysed quantitatively and qualitatively, and in order to keep the identity of the respondents confidential, the results were published as percentages. Given that all questions in the questionnaire were with multiple choice answers, the percentages gathered per question cannot be analysed as part of the whole $(100 \%)$.

\section{The results}

The first question of the questionnaire ("Did your company establish dispute resolution policies regarding international trade contracts with pharmaceuticals?") aims to determine to what extent the pharmaceutical companies implemented internal procedures / policies for effective prevention and resolution of disputes international trade. Analysing the results of the questionnaire, we acknowledged that the majority of respondents either claimed that the companies in which they were operating implemented internal policies that included standard contractual clauses on how to settle disputes (36.4\% of respondents) or that company policies contain guides for choosing the means of resolving disputes $36.4 \%$ of respondents). Only $13.6 \%$ responded that they did not implement internal dispute resolution policies regarding international trade contracts with pharmaceuticals, but each contract is individually analysed, negotiated and agreed on with the external partner.

\section{Question no. 1}

1. Did your company establish dispute resolution policies regarding to international trade contracts with pharmaceuticals?

Yes, our company policies contain...

Yes, our company policies contain...

No, every contract is analysed... Not possible to say / none in particular Other

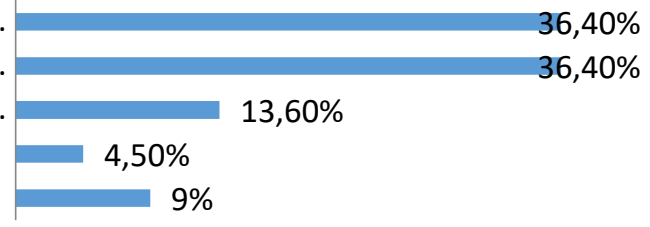


The second question refers to the criteria used when choosing how to settle disputes in international trade agreements with pharmaceuticals. Having considered the criteria, in order of importance, the respondents considered that the choice of the dispute resolution method is conditioned by: the overall cost of service $(77.3 \%)$, the confidentiality of the procedure $(59.1 \%)$, the procedure speed $(40.9 \%)$, the recognition and enforcement of the award $(36,4 \%)$, the flexibility of the procedure $(31,8 \%)$, the possibility of a satisfactory result $(18,2 \%)$, the expertise in a certain type of litigation $(18,2 \%)$, the company policy, standard terms and conditions $(13.6 \%)$ and specialized and qualified neutrals (e.g. judges, arbitrators, mediators) (13.6\%).

\section{Question no. 2}

2. What criteria are taken into consideration when choosing a dispute resolution method to solve arising litigation regarding international trade contracts with pharmaceuticals?

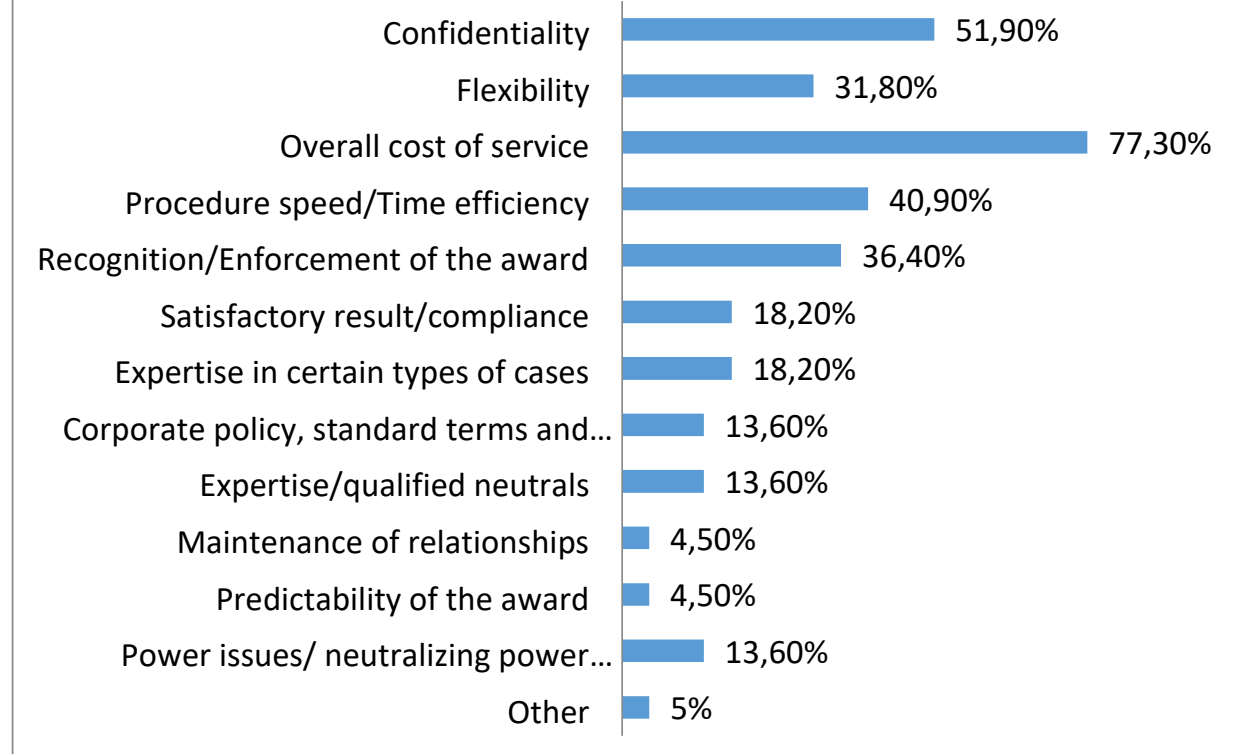

The answers to the third question had the purpose to identify the means preferred by the practitioners for solving disputes related to international pharmaceutical trade contracts. Surprisingly, litigation in state courts is the most popular among the respondents, 50\% choosing this option. Only $31.8 \%$ choose amicable settlement options with the possibility of escalation to arbitration, while only $22.7 \%$ of the respondents choose 
arbitration as the sole method of resolving the dispute. At the same time, $13.6 \%$ of respondents consider that they can solve the litigation exclusively through alternative dispute resolution (ADR).

\section{Question no. 3}

3. What form of dispute resolution does your company prefer to choose in order to solve arising disputes from international trade contracts with pharmaceuticals?

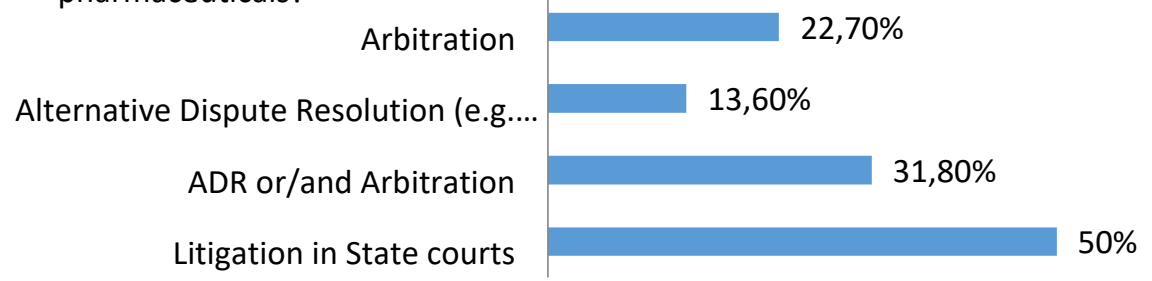

The fourth question seeks to identify the criteria that are taken into account when choosing the applicable law on the international trade dispute. Among the criteria for the choice of the applicable law to the litigation, the respondents considered as determinant: the knowledge of the law by the parties or by one of the contracting parties ( $72.7 \%$ of the answers), the neutrality of the law in the sense that its application will not disadvantage either party $(54.5 \%)$, the similarity to the national law of home jurisdiction $(31.8 \%)$ and the place where the contract will be executed (18.2\%).

\section{Question no. 4}

4. What criteria are taken into consideration when choosing the law governing the substance of the dispute/applicable law?

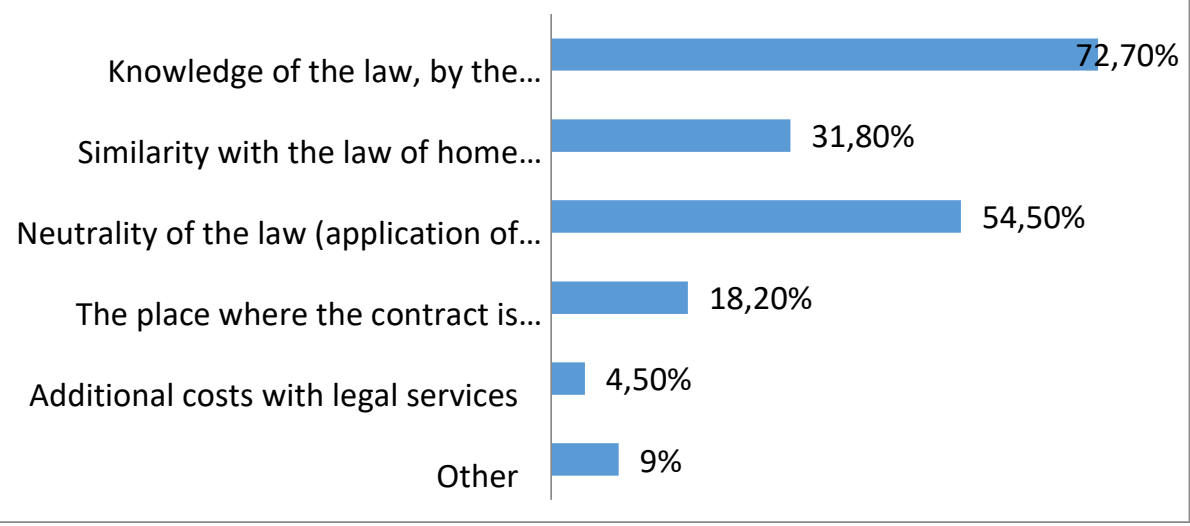


The fifth question of the questionnaire has intended to find out what is the applicable law that is chosen the most often by pharmaceutical companies` legal counsels to govern international trade contracts. Questioned about the applicable law that is frequently chosen to govern international contracts with pharmaceuticals, $81.8 \%$ of the respondents chose the law of home jurisdiction, $40.9 \%$ the law of a third country other than that of the contracting parties' jurisdiction (neutral law), $4.5 \%$ international treaties or conventions and $4.5 \%$ general principles of law, commercial practices and lex mercatoria.

\section{Question no. 5}

5. What applicable law does your company normally choose to govern the international trade contracts?

\begin{tabular}{r|rr} 
Law of home jurisdiction & & $81,80 \%$ \\
Neutral law & & $40,90 \%$ \\
General principles of law, commercial... & $4,50 \%$ & \\
International treaties or conventions... & $4,50 \%$ & \\
Other & $9 \%$ &
\end{tabular}

The sixth question regarded the arbitration institutions and the appropriate set of rules to any litigation in the pharmaceutical industry. Thus, from perspective of the arbitration institution and the rules considered appropriate to solve international trade disputes with pharmaceuticals, the answers varied, the preferred being: the ICC International Court of Arbitration Paris, on a par with the Swiss Chamber's Arbitration Institution (31.8\% of the respondents), followed by the American Arbitration Association and International Center for Dispute Resolution (27.3\%), the London Court of International Arbitration (18.2\%), the Vienna International Arbitral Center (13.6\%). The least preferred were the Arbitral Center of the World Intellectual Property Organization (4.5\%), the Singapore International Arbitration Center (4.5\%) and the Chinese International Economic and Trade Arbitration Center (4.5\%). 


\section{Question no. 6}

6. Considering your company international trade contracts, what arbitration institution and set of rules would be suitable for any kind of pharmaceutical industry disputes?

ICC International Court of Arbitration...

Arbitral Center of the World..

London Court of International... $4,50 \%$

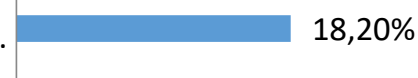

American Arbitration Association and...

$27,30 \%$

Swiss Chamber's Arbitration..

$31,80 \%$

Vienna International Arbitral Center \&...

Singapore International Arbitration..

$4,50 \%$

Stockholm Chamber of Commerce..

Chinese International Economic and..

Other

$13,60 \%$

$9,10 \%$

$4,50 \%$

$9 \%$

The seventh question has intended to identify the factors that determine the choice of a particular arbitration institution to resolve disputes of international trade with pharmaceuticals. Among the criteria underlying the choice of the arbitration institution, respondents considered as determinants: the neutrality ( $54.5 \%$ of the respondents), the overall cost of service $(45.5 \%)$, the law governing the substance of the dispute $(45.5 \%)$, the seat chosen for the arbitration (36.4\%), the corporate policy, standard terms and conditions $(27.3 \%)$, the reputation and recognition of the arbitration institution (18.2\%) and the arbitration rules (9\%). 
Settlement Methods of International Trade Disputes in the Pharmaceutical ... Ștefan Răzvan TATARU

\section{Question no. 7}

7. What criteria are taken into consideration when choosing the arbitration institution?

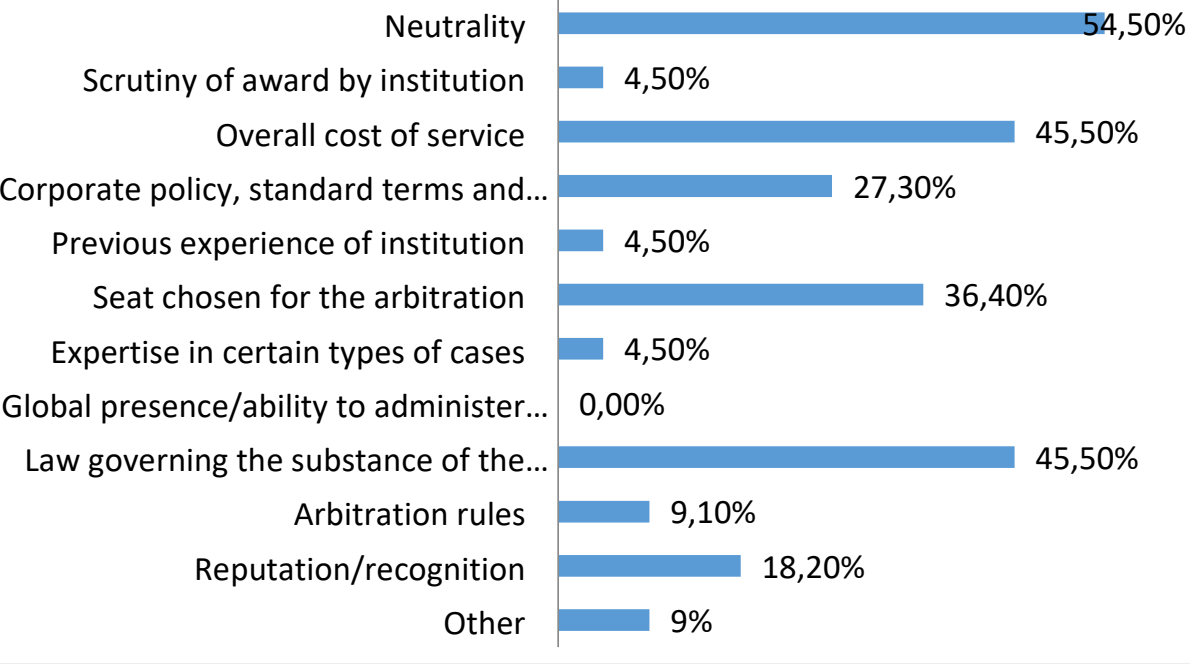

The eighth question of the questionnaire aimed to identify the criteria underlying when choosing the seat of arbitration. Respondents' answers point out that the most important criteria are: the law governing the substance of the dispute $(81.8 \%$ of respondents), the location of the arbitration institution chosen for the arbitration (45.5\%) and convenience (e.g. location, industry specific usage/prior use by organisation, language/culture and efficiency of court proceedings) (31.8\%). At the same time, the choice of the seat of arbitration can also be influenced by: formal legal infrastructure (e.g. the national arbitration law, track record in enforcing agreements to arbitrate and arbitral awards, neutrality and impartiality of the legal system) $(22.7 \%)$, corporate policy, standard terms and conditions $(22.7 \%)$, general infrastructure (e.g. costs, access, physical infrastructure) $(18.2 \%)$ and the recommendation of an external legal counsel (4.5\%). 


\section{Question no. 8}

8. What criteria are taken into consideration when choosing the seat of arbitration?

\begin{tabular}{|c|c|c|}
\hline Formal legal infrastructure (e.g. the... & $22,70 \%$ & \\
\hline Law governing the substance of the... & & $81,80 \%$ \\
\hline Convenience (e.g. location, industry... & $31,80 \%$ & \\
\hline General infrastructure (e.g. costs,... & $18,20 \%$ & \\
\hline Corporate policy, standard terms and... & $22,70 \%$ & \\
\hline Location of people (e.g. your company... & $9,10 \%$ & \\
\hline Location of the arbitration institution... & $45,50 \%$ & \\
\hline Choice of seat imposed by other party & $0,00 \%$ & \\
\hline Recommendation of external counsel & $4,50 \%$ & \\
\hline Other & $5 \%$ & \\
\hline
\end{tabular}

From the answers to the penultimate question, we can analyse in what order the law applicable, the place of arbitration and the arbitration institution are chosen and how they influence each other. According to the answers, $81.8 \%$ of the respondents initially chose the applicable law and then the place and the arbitration institution, while 31.8\% choose the applicable law and then the arbitration institution and its place. Only 13.6\% of respondents believe that the order of the choices has no influence on each other, these being independent. 


\section{Question no. 9}

9. In what order the choices about governing law, seat and institution/rules are made and how they influence one another?

Governing law, seat of arbitration, arbitration institution/rules

Governing law, arbitration institution/rules, seat of arbitration Seat of arbitration, arbitration institution/rules, governing law

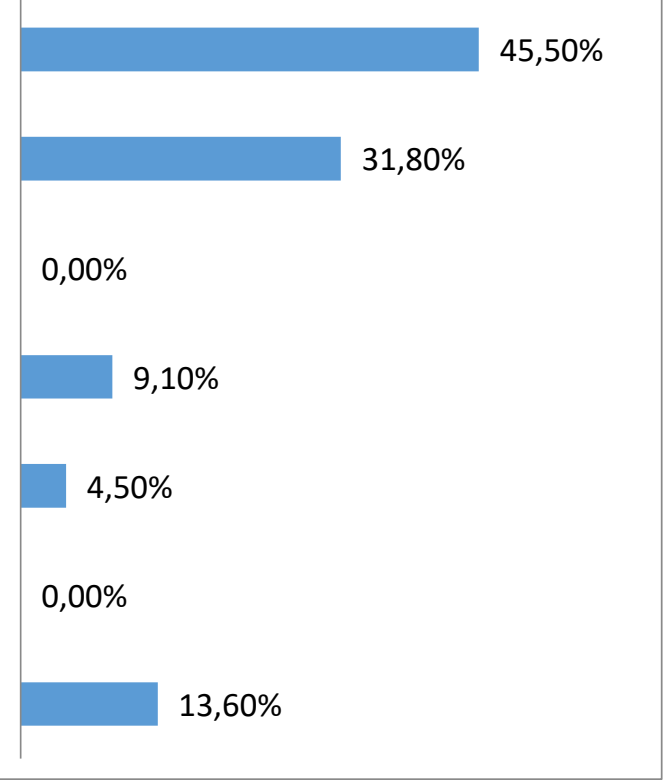

Seat of arbitration, governing law, arbitration institution/ rules

Arbitration institution/rules, seat of arbitration, governing law

Arbitration institution/rules, governing law, seat of arbitration

The order of choices has no influence on one or another

For a better understanding of the determining factors and the reasons why a contracting party prejudiced by the breach of contractual obligations initiates an arbitration process, the final question of the questionnaire has sought to achieve a hierarchy of these factors. According to respondents, the initiation of an arbitration process is primarily influenced by the strength of the legal positions and arguments $(63.6 \%$ of the respondents) followed by the possibility of recovering the damage $(45 \%)$, the ease of enforcement of award / the solvency of the debtor (27.3\%), the likely legal costs $(27.3 \%)$ and the strength of evidence $(18.2 \%)$. 


\section{Question no. 10}

10. What factors influence the decision to initiate arbitration proceedings?

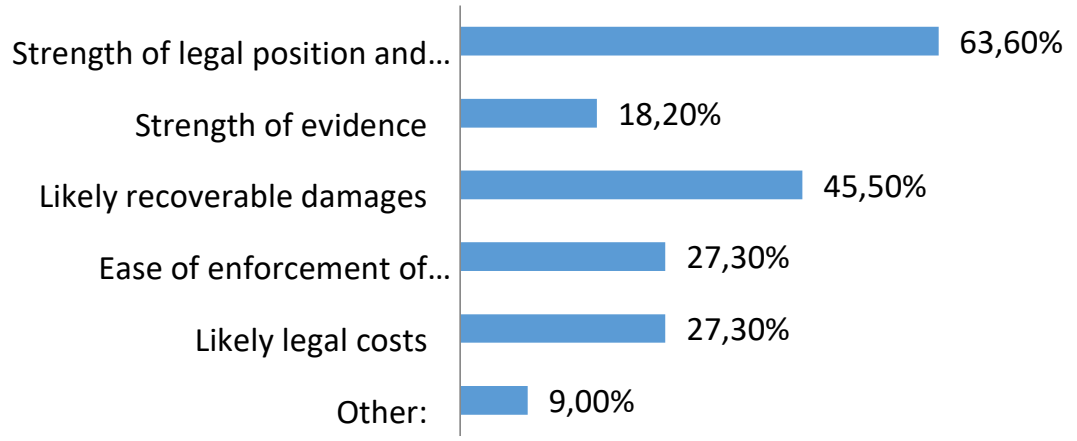

2. Analysis of international trade agreements with pharmaceuticals

\section{A. Identification and selection of international trade agreements with pharmaceuticals}

In order to validate the results obtained through the use of the questionnaire method, we proceeded to the empirical analysis of the applicable law clauses and the dispute resolution clauses in the international trade contracts with pharmaceuticals, used in practice by the respondent companies. Considering the confidentiality of the data contained in such commercial contracts and, implicitly, the improbability of having access to such documents in force at the date of the present study, there were identified and analysed international trade agreements concluded between 2012-2017.

International trade agreements with pharmaceutical products are complex contracts containing a multitude of confidential information, this being one of the reasons why the documents under this analysis have been identified using the Lawinsider.com online database,-which includes contracts concluded by pharmaceutical companies in their international trade operations.

International trade with pharmaceuticals involves complex operations that cannot be exclusively regulated through supply agreements or sales contracts, which has led to the selection of a wider range of contracts including, but not limited to: Licence and Supply Agreements, Distribution Agreements, Non-Disclosure Agreements, License and Development Agreements. 
There have been selected sixty-six contracts concluded by pharmaceutical companies from more than 20 countries, such as: Belgium, China, Denmark, France, Germany, India, Italy, Israel, Japan, the Netherlands, Norway, Puerto Rico, Romania, South Korea, Singapore, Spain, Sweden, Switzerland, the United Kingdom of Great Britain and Ireland and the United States of America.

\section{B. The analysis of contractual clauses}

Subsequently to the selection of the sixty-six contracts was the phase of their analysis to extract information on how the applicable law and the dispute resolution method were chosen by the contracting parties. The research consisted in the analysis of the contract's preamble for the identification of the contracting parties' headquarters, the purpose and object of the contract and later, of the dispute resolution and applicable law clauses.

The collected data from the selected contracts were processed in order to extract the results through a quantitative method, as a percentage.

\section{The results of the analysis of contractual clauses}

Following the analysis of the contractual clauses on how to solve potential disputes, we noticed that $39.4 \%$ of the pharmaceutical companies chose the state courts as dispute resolution method, $36.4 \%$ the arbitration, $19.7 \%$ the ADR means with escalation to arbitration and, only $3 \%$ preferred the ADR exclusively.

If we analyse the contractual terms with respect to the headquarters of the contracting parties, we will notice that the applicable law in $68.2 \%$ of cases is the national law of one of the contracting parties, in $27.3 \%$ of cases a neutral law, while in $4.5 \%$ of cases the parties did not choose the applicable law.

Regarding the criteria for choosing the place to settle disputes, either through arbitration or before the state courts, we noticed from the analysis of the contracts that either the choice was made having regard to the seat of one of the contracting parties, or that a neutral jurisdiction is looked more favourable upon. Thus, from the contractual clauses that have been analysed, in $53 \%$ of the cases the disputes were to be settled in the state where one of the contracting parties had their headquarters, in $36.4 \%$ in a neutral jurisdiction, and in $10.6 \%$ of the contracts the place of settlement of the dispute was not chosen.

Referring to the arbitration clauses in the analysed contracts, we can observe that among the permanent arbitration institutions chosen by the 
pharmaceutical companies are the following: ICC International Court of Arbitration Paris (27.3\%), the American Arbitration Association (13.6 \%), the U.S. Judicial Arbitration and Mediation Services (JAMS, in the United States), the Hong Kong International Arbitration Center (HKIAC) and others.

\section{Personal remarks / Conclusions}

The legal doctrine regarding the settlement of international disputes with pharmaceutical products is either non-existent, vague, referring extensively to life-sciences disputes that include the medical, pharmaceutical and biotechnology sector. However, the existing bibliographic sources present arbitration as the most suitable and preferred method by the participants in the international trade with pharmaceuticals when addressing potential disputes that are arising in their commercial cooperation. The present empirical legal research, both through the results of the questionnaire and the analysis of the contractual clauses, contradicts the majority opinion of the international legal doctrine, highlighting the fact that, in practice, pharmaceutical companies prefer state courts to settle disputes, to the detriment of arbitration which occupies a second place.

Arbitration may be considered the desirable method to solve international disputes in the pharmaceutical industry given the advantages they present, but at the moment the courts are the forum often chosen by the legal counsels of pharmaceutical companies. If we take into consideration the statistical data of the arbitration institutions, we can notice, according to the published annual reports, that medical-pharmaceutical disputes represent $3.7 \%$ of the total number of cases at ICC (ICC, 2016), $3.16 \%$ at LCIA (London Court of International Arbitration ,2016), respectively $20.22 \%$ at HKIAC (Hong Kong International Arbitration Centre, 2016), all increasing compared to previous years.

The results of the present empirical legal research do not contradict the legal doctrine on the settlement of international trade disputes from the pharmaceutical industry. We believe that arbitration has multiple advantages and features to resolve disputes of international trade with pharmaceuticals, but at the moment most of these disputes are settled either through conciliation or before the courts.

\section{References}

Hong Kong International Arbitration Centre (2016). Annual Report 2016 Reflections, (retrieved from: 
Settlement Methods of International Trade Disputes in the Pharmaceutical ... Ştefan Răzvan TATARU

http://www.hkiac.org/sites/default/files/annual report/annual\%20 report $\% 202016 \% 20 \% 281$ ow $\% 20$ resolution $\% 29 \% 20$ v2.pdf.)

International Chamber of Commerce (2016). Statistical Report. Retrieved from http://library.iccwbo.org/dr-statisticalreports.htm.)

London Court of International Arbitration (2016). Facts and Figures 2016 A Robust Caseload. Retrieved from:

http://www.lcia.org//media/download.aspx?MediaId=570.) 